\title{
Características da Carcaça de Novilhos de Gerações Avançadas do Cruzamento Alternado entre as Raças Charolês e Nelore, Terminados em Confinamento ${ }^{1}$
}

\author{
Luís Fernando Glasenapp de Menezes ${ }^{2}$, João Restle ${ }^{3}$, Ivan Luiz Brondani ${ }^{4}$, Dari Celestino \\ Alves Filho ${ }^{5}$, Fernando Kuss ${ }^{6}$, Magali Floriano da Silveira ${ }^{7}$, Gláucia Azevedo do Amaral ${ }^{7}$
}

\begin{abstract}
RESUMO - Foram avaliadas as características quantitativas da carcaça de novilhos puros (Charolês - C e Nelore - N) e mestiços da segunda (G2) $(3 / 4 \mathrm{C} 1 / 4 \mathrm{~N}$ e $3 / 4 \mathrm{~N} \mathrm{1/4C)}$, terceira (G3) (5/8C 3/8N e 5/8N 3/8C) e quarta $(\mathrm{G} 4)(11 / 16 \mathrm{C} 5 / 16 \mathrm{~N}$ e $11 / 16 \mathrm{~N} \mathrm{5/16C)}$ gerações de cruzamento, terminados em confinamento. Os animais mestiços apresentaram maiores pesos de abate e de carcaças quente e fria que a média dos puros, com heterose total, respectivamente, de 14,95; 18,72 e 18,39\% na G2, 19,98; 24,16 e 24,59\% na G3, e 18,38; 22,55 e $22,88 \%$ na G4. A heterose total para as três características acompanhou as oscilações do grau de heterozigose individual. As heteroses para rendimento de carcaça quente e fria foram significativas em todas as gerações do cruzamento, sendo a heterose retida 3,22 e 3,71\%, respectivamente. A perda de líquidos durante o resfriamento da carcaça na G2 não diferiu dos animais puros, mas foi significativamente menor na G3 (-16,73\%) e na G4 (-12,84\%). Para maturidade fisiológica da carcaça, a heterose foi negativa e significativa na G3 e na G4. A espessura de gordura foi maior nos mestiços das três gerações de cruzamento, mas foi significativa apenas na G4. Para as características que expressam a musculosidade da carcaça, a heterose foi significativa nas três gerações para conformação e área do músculo Longissimus dorsi, para espessura de coxão e perímetro de braço, embora positiva nas três gerações, alcançou significância na G3 e na G4, sendo a heterose retida de 8,$09 ; 11,33 ; 7,45$ e 5,95\%, respectivamente. As características relacionadas ao desenvolvimento corporal apresentaram heterose significativa em todas as gerações de cruzamento, sendo a heterose retida de 8,55; 5,73 e 4,99\% para comprimento de carcaça, de perna e de braço, respectivamente. A proporção dos cortes comerciais na carcaça não foi afetada pela heterozigose, mas, para os seus valores absolutos, a heterose foi significativa, acompanhando o comportamento do peso da carcaça.
\end{abstract}

Palavras-chave: Bos indicus, Bos taurus, cortes comerciais, gordura subcutânea, heterose

\section{Carcass Characteristics of Feedlot Finished Steers from Advanced Generations of Rotational Crossbreeding between Charolais and Nellore Breeds}

\begin{abstract}
The objective of this work was to evaluate the carcass characteristics of feedlot finished steers, straightbreds (Charolais - $\mathrm{C}$ and Nellore - N), and crossbreds from second (G2) $(3 / 4 \mathrm{C} 1 / 4 \mathrm{~N}$ and $3 / 4 \mathrm{~N} 1 / 4 \mathrm{C})$, third (G3) (5/8C 3/8N and 5/8N 3/8C) and fourth (G4) (11/16C 5/16N and 11/16N 5/16C) generations of rotational crossbreeding. Crossbreds showed higher slaughter, hot and cold carcass weights than the average of the purebreds, being the total heterosis, respectively, $14.95 ; 18.72$ and $18.39 \%$ in G2, 19.98; 24.16 and $24.59 \%$ in G3 and, $18.38 ; 22.55$ and $22.88 \%$ in G4. Total heterosis for the three characteristics followed the fluctuation of individual heterozygosis. Heterosis for hot and cold carcass dressing percentage was significant in all generations, being the retained heterosis, respectively, 3.22 and $3.71 \%$. Carcass chilling loss in G2 did not differ from purebreds, but was significantly lower in G3 (-16.73\%) and G4 (-12.84\%). For carcass physiological maturity, heterosis was negative and significant in G3 and G4. Subcutaneous fat thickness was higher for the crossbreds of the three generations, however, was only significant in G4. For the characteristics related to carcass muscling, heterosis was significant in the three generation for conformation and Longissimus dorsi area, for cushion thickness and arm perimeter, although positive in the three generations, reached significance only in G3 and G4, being the retained heterosis, respectively, $8.09 ; 11.33 ; 7.45$ and $5.95 \%$. The characteristics related to corporal development showed significant heterosis in all generations, being the retained heterosis $8.55 ; 5.73$ and $4.99 \%$, respectively, for carcass, leg and arm length. The proportion of commercial cuts of the carcass was not affected by heterozygosis, but for their absolute values, heterosis was significant following the carcass weight behavior.
\end{abstract}

Key Words: Bos indicus, Bos taurus, commercial cuts, heterosis, subcutaneous fat

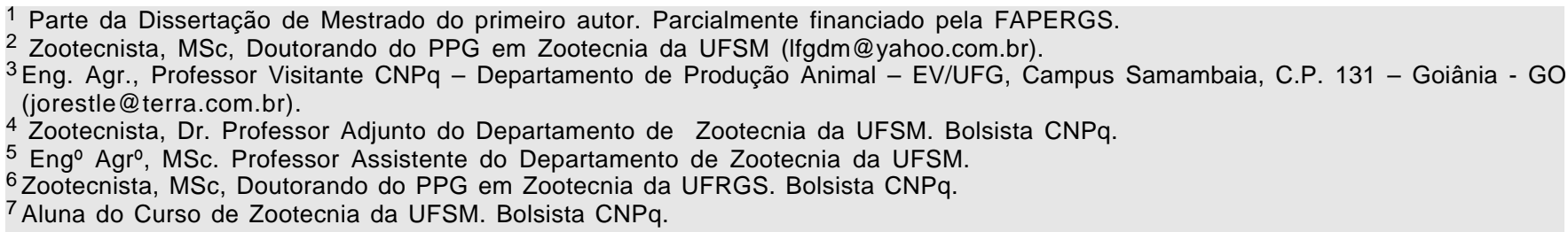




\section{Introdução}

As características da carcaça de bovinos de corte vêm ganhando cada vez mais importância no cenário nacional, principalmente em função do aumento nas exportações e da crescente exigência do mercado internacional. Mercados importadores exigem músculos com peso elevado, uniformes e de qualidade. Com isso, o grupo genético escolhido na utilização da prática do confinamento se torna ainda mais importante, uma vez que há diferenças marcantes nas carcaças de diferentes genótipos.

Entre as raças de produção de carne, Charolês é uma das principais no que se refere à participação de músculos na carcaça (De Rouen et al., 1992). Porém, animais deste genótipo são tardios, depositando tecido adiposo em fase avançada da vida (Vaz et al., 2002). A raça Nelore, além de ser relativamente precoce na deposição de gordura subcutânea, apresenta vantagem no rendimento de carcaça (Restle et al., 2002). Essa raça, porém, apresenta baixa expressão muscular, quando comparada à raça Charolês (Restle et al., 2000).

Buscando incorporar estas características, importantes para os vários segmentos da cadeia da carne (produtor, frigorífico, mercado varejista e consumidor), nos rebanhos comerciais do sul do país, o cruzamento entre raças que se complementam, como a Charolês e a Nelore, vêm se tornando cada vez mais rotineiros. O sucesso deste tipo de cruzamento é o alto nível de heterose originária da grande distância genética entre os grupos Bos taurus e Bos indicus (Koger, 1980).

Segundo Perotto et al. (2000), a carcaça do animal cruzado pode ser otimizada pela combinação das características superiores das raças paternas, ou seja, a partir de cruzamentos entre raças, os pecuaristas podem manipular importantes características, como grau de acabamento, em função de peso de abate, percentagem de cortes nobres e padrão de deposição de gordura. Portanto, o cruzamento de bovinos de corte é uma importante ferramenta para o produtor, pois facilita a rápida introdução, no rebanho, de características desejáveis, explorando a complementaridade das raças e, principalmente, permitindo explorar o efeito da heterose.

O objetivo neste experimento foi avaliar as características quantitativas e qualitativas, além da proporção dos cortes comerciais da carcaça e a heterose de novilhos de segunda, terceira e quarta gerações do cruzamento alternado das raças Charolês e Nelore, terminados em confinamento.

\section{Material e Métodos}

O trabalho foi realizado no Setor de Bovinocultura de Corte do Departamento de Zootecnia da Universidade Federal de Santa Maria (UFSM).

Comparou-se o efeito da composição racial e a heterose nas características quantitativas da carcaça de novilhos puros (Charolês - C e Nelore - N) e mestiços de segunda $(\mathrm{G} 2)(3 / 4 \mathrm{C} 1 / 4 \mathrm{~N}$ e $3 / 4 \mathrm{~N} 1 / 4 \mathrm{C})$, terceira (G3) $(5 / 8 \mathrm{C} 3 / 8 \mathrm{~N} \mathrm{e} 5 / 8 \mathrm{~N} 3 / 8 \mathrm{C})$ e quarta $(\mathrm{G} 4)(11 / 16 \mathrm{C}$ $5 / 16 \mathrm{~N}$ e $11 / 16 \mathrm{~N} 5 / 16 \mathrm{C})$ gerações de cruzamento. A heterose apresentada neste trabalho é a total, decorrente da heterozigose individual e materna.

Foram utilizados 78 novilhos, tomados ao acaso da fazenda experimental da UFSM, nascidos na mesma época de parição e mantidos sempre sob as mesmas condições de manejo e alimentação. Os novilhos foram gerados por fêmeas puras e mestiças inseminadas com sêmen de seis touros de cada raça (Charolês e Nelore). Quatro touros de cada raça foram utilizados para o repasse na monta a campo. Os touros Charolês que geraram os novilhos Charolês foram os mesmos que geraram os novilhos $3 / 4 \mathrm{C} 1 / 4 \mathrm{~N}, 5 / 8 \mathrm{C} 3 / 8 \mathrm{~N}$ e $11 / 16 \mathrm{C}$ $5 / 16 \mathrm{~N}$, assim como os touros Nelore que geraram os novilhos Nelore foram os mesmos que geraram os novilhos 3/4N 1/4C, 5/8N 3/8C e 11/16N 5/16C.

Ao início do período de terminação em confinamento, os animais apresentavam, em média, 20 meses de idade. Os animais $\mathrm{C}, \mathrm{N}, 3 / 4 \mathrm{C} 1 / 4 \mathrm{~N}, 3 / 4 \mathrm{~N}$ $1 / 4 \mathrm{C}, 5 / 8 \mathrm{C} 3 / 8 \mathrm{~N}, 5 / 8 \mathrm{~N} 3 / 8 \mathrm{C}, 11 / 16 \mathrm{C} 5 / 16 \mathrm{~N}$ e $11 / 16 \mathrm{~N}$ $5 / 16 \mathrm{C}$ apresentavam no início do período de confinamento, ainda, 274,4;241,1;299,6; 317,3; 320,$2 ; 339,4 ; 333,7 ; 305,8 \mathrm{~kg}$, respectivamente. O período total de confinamento teve duração de 97 dias, sendo que, nos primeiros 14 dias de confinamento, os animais foram submetidos à adaptação ao ambiente do confinamento e à dieta alimentar. A dieta, igual para todos os animais, foi calculada para proporcionar ganho de peso médio diário (GMD) de 1,2 kg (NRC, 1996) e apresentou 12,32\% de proteína bruta (PB), 2,96 Mcal de energia digestível e 58,30\% de fibra em detergente neutro (FDN). O volumoso, representando $52 \%$ da matéria seca total oferecida, foi constituído de silagem de milho (AG 5011). O concentrado foi composto por 93,97\% de farelo de trigo, $1,5 \%$ de uréia, $3,62 \%$ de calcário calcítico e $0,9 \%$ de sal. Adicionado ao concentrado constava, ainda, monensina sódica, em quantidade recomendada pelo fabricante $(200 \mathrm{mg} /$ animal/dia). 
Após 97 dias de confinamento, os animais foram pesados, após jejum de sólidos de 14 horas, e embarcados para um frigorífico comercial, onde foram abatidos logo após a chegada, obedecendo o fluxo normal do estabelecimento. Após o abate, as carcaças foram identificadas, pesadas e levadas para uma câmara fria, onde permaneceram por 24 horas a $0^{\circ} \mathrm{C}$. Após este tempo, foram novamente pesadas e, seguindo a metodologia descrita por Müller (1987), avaliou-se a conformação e a maturidade fisiológica da carcaça.

A metade esquerda da carcaça foi separada em dianteiro, costilhar (ponta de agulha) e serrote (traseiro especial) e cada peça foi pesada, para posterior cálculo de sua porcentagem em relação à carcaça inteira.

$\mathrm{Na}$ meia-carcaça direita, foram mensurados, segundo Müller (1987), os comprimentos de carcaça, de perna e de braço, a espessura de coxão e o perímetro de braço. Entre a $12^{\mathrm{a}}$ e a $13^{\mathrm{a}}$ costelas, realizou-se um corte horizontal visando expor o músculo Longissimus dorsi, para traçar o seu contorno em papel vegetal, sendo a área da figura posteriormente determinada em mesa digitalizadora. No mesmo local, foi medida a espessura de gordura subcutânea obtida pela média de duas observações.

O delineamento experimental adotado foi o inteiramente casualizado, com número diferente de repetições por grupo genético (seis repetições para os grupos $\mathrm{C}, 3 / 4 \mathrm{C} 1 / 4 \mathrm{~N}$ e $11 / 16 \mathrm{~N} 5 / 16 \mathrm{C}$; nove repetições para os grupos $3 / 4 \mathrm{~N} 1 / 4 \mathrm{C}$ e $11 / 16 \mathrm{C} 5 / 16 \mathrm{~N}$; 12 repetições para o grupo 5/8C 3/8N; e 15 repetições para os grupos $\mathrm{N}$ e $5 / 8 \mathrm{~N} \mathrm{3/8C)}$ ).

Os dados foram analisados pela análise de variância e as médias foram comparadas pelo teste t (SAS, 1997), empregando-se o seguinte modelo estatístico:

$$
Y_{i j k l}=m+I V_{k}+S A_{i}+G_{j}\left(S A_{i}\right)+E_{i j k l}
$$

em que $\mathrm{Y}_{\mathrm{ijkl}}$ refere-se às variáveis dependentes; m, à média de todas as observações; $\mathrm{IV}_{\mathrm{k}}$, ao efeito da $\mathrm{k}$ ésima idade da vaca, mãe do novilho; $\mathrm{SA}_{\mathrm{i}}$, ao efeito do sistema de acasalamento de índice $i$, sendo $i=1$ (puros), 2 (mestiços da G2), 3 (mestiços da G3) e 4 (mestiços da G4); $\mathrm{GG}_{\mathrm{j}}\left(\mathrm{SA}_{\mathrm{i}}\right)$, efeito do grupo genético de índice $j$ aninhado dentro do sistema de acasalamento i, sendo j = 1 (Charolês) e 2 (Nelore) dentro do SA 1 ; $1\left(3 / 4 \mathrm{C}^{1 / 4} \mathrm{~N}\right)$, e $2\left(3 / 4 \mathrm{~N}^{1 / 4} \mathrm{C}\right)$ dentro do SA $2 ; 1$ (5/8C $3 /$ $8 \mathrm{~N})$ e $2(5 / 8 \mathrm{~N} 3 / 8 \mathrm{C})$ dentro do SA $3 ; 1$ (11/16C $5 /$ $16 \mathrm{~N})$ e $2\left(11 / 16 \mathrm{~N} \mathrm{5/16} \mathrm{C)} \mathrm{dentro} \mathrm{do} \mathrm{SA} \mathrm{4;} \mathrm{E}_{\mathrm{ijk}}\right.$, efeito aleatório residual.

Também foi calculada a heterose resultante das características avaliadas nas diferentes gerações de cruzamento:

H\%=[(média dos mestiços dentro de cada geração média dos puros)-1] x 100.

A heterose retida foi calculada pela seguinte equação: Hretida $=[$ (média de todos os mestiços/média dos puros)-1] x 100 .

\section{Resultados e Discussão}

As médias e a heterose referentes aos pesos de abate e de carcaça quente e fria, aos rendimentos de carcaça quente e fria e à quebra no resfriamento constam na Tabela 1.

Os animais mestiços apresentaram maiores pesos de abate e de carcaça quente e fria que a média dos puros, sendo a heterose, respectivamente, de 14,$95 ; 18,72$ e $18,39 \%$ na G2, 19,$98 ; 24,16$ e $24,59 \%$ na G3 e de 18,$38 ; 22,55$ e $22,88 \%$ na G4. Verifica-se que a heterose, para as três características, acompanhou as oscilações do grau de heterozigose individual, que foi de $50 \%$ na G2, 75\% na G3, voltando a cair para $62,5 \%$ na G4. Koger et al. (1975) foram os que inicialmente comprovaram a linearidade entre heterose e heterozigose. Trabalhando com animais oriundos do mesmo projeto que gerou os animais utilizados neste estudo, Vaz (1999) e Restle et al. (2000) verificaram que a heterose, para as características acima citadas, caiu da G1 para a G2, acompanhando a queda no grau de heterozigose. Perotto et al. (1999) e Perotto et al. (2000), estudando as características de carcaça de animais de dois sistemas de cruzamento alternado, Canchim-Aberdeen Angus e Charolês-Caracu, também observaram que a heterose para peso de carcaça quente aumentou da G2 para a G3.

Espera-se que a heterose para peso de carcaça nas futuras gerações de cruzamento se mantenha próxima aos níveis da G4 $(22,55 \%)$, muito similar à heterose retida $(22,21 \%)$, tendo em vista que, nesta geração de cruzamento, a heterozigose é próxima àquela verificada quando o cruzamento rotativo se estabiliza, ou seja, 66,67\% da F1.

Comparando as raças puras, constata-se que a Charolês apresentou peso de carcaça quente $24 \%$ superior à Nelore. Diferenças de 24 e $17 \%$ no peso de carcaça quente entre novilhos dos dois grupos genéticos terminados em confinamento aos 24 meses são relatadas, respectivamente, por Restle et al. (1995a) e Restle et al. (2000). Também em vacas de 
Tabela 1 - Médias, erros-padrão e heterose para peso de abate (PAB), pesos de carcaça quente (PCQ) e fria (PCF), rendimento de carcaças quente (RCQ) e fria (RCF) e quebra ao resfriamento (QR) da carcaça de novilhos, de acordo com geração de cruzamento e grupo genético

Table 1 - Means, standard errors and heterosis for slaughter weight (PAB), hot (PCQ) and cold (PCF) carcass weight, hot (RCQ) and cold $(R C F)$ carcass dressing percentage, chilling loss (QR) of the carcass of steers, according to crossbreeding generation and genetic group

\begin{tabular}{|c|c|c|c|c|c|c|}
\hline $\begin{array}{l}\text { Grupo genético } \\
\text { Genetic group }\end{array}$ & $\mathrm{PAB}, \mathrm{kg}$ & PCQ, kg & $\mathrm{RCQ}, \%$ & $\mathrm{PCF}, \mathrm{kg}$ & $\mathrm{RCF}, \%$ & $\mathrm{QR}, \%$ \\
\hline $\begin{array}{l}\text { Charolês }(\mathrm{C}) \\
\text { Charolais }(C)\end{array}$ & $414,7 \pm 22,0^{\mathrm{a}}$ & $226,1 \pm 13,9^{\mathrm{a}}$ & $54,4 \pm 0,7^{b}$ & $220,1 \pm 13,6^{\mathrm{a}}$ & $52,9 \pm 0,7^{b}$ & $2,7 \pm 0,3$ \\
\hline $\begin{array}{l}\text { Nelore }(\mathrm{N}) \\
\text { Nellore }(N)\end{array}$ & $324,8 \pm 18,0^{\mathrm{b}}$ & $182,8 \pm 8,8^{b}$ & $56,2 \pm 0,4^{\mathrm{a}}$ & $178,3 \pm 8,6^{b}$ & $54,8 \pm 0,4^{\mathrm{a}}$ & $2,5 \pm 0,2$ \\
\hline $\begin{array}{l}\text { Média puros } \\
\text { Straightbreds mean }\end{array}$ & $369,8 \pm 13,0$ & $204,4 \pm 8,2$ & $55,3 \pm 0,4$ & $199,2 \pm 8,0$ & $53,9 \pm 0,4$ & $2,6 \pm 0,2$ \\
\hline $\begin{array}{l}\text { 3/4C 1/4N } \\
3 / 4 \mathrm{~N}^{1 / 4} \mathrm{C} \\
\text { Média G2 }\end{array}$ & $\begin{array}{l}421,6 \pm 21,9 \\
432,2 \pm 18,0 \\
426,9 \pm 14,2\end{array}$ & $\begin{array}{l}241,6 \pm 13,8 \\
245,4 \pm 11,4 \\
243,5 \pm 8,9\end{array}$ & $\begin{array}{l}57,3 \pm 0,7 \\
56,6 \pm 0,6 \\
57,0 \pm 0,5\end{array}$ & $\begin{array}{l}233,9 \pm 13,6 \\
239,7 \pm 11,1 \\
236,8 \pm 8,8\end{array}$ & $\begin{array}{l}55,5 \pm 0,7 \\
55,3 \pm 0,5 \\
55,4 \pm 0,5\end{array}$ & $\begin{array}{l}3,2 \pm 0,3^{\mathrm{a}} \\
2,3 \pm 0,3^{\mathrm{b}} \\
2,8 \pm 0,2\end{array}$ \\
\hline $\begin{array}{l}\text { G2 means } \\
\text { Heterose G2, \% } \\
\text { G2 heterosis. \% }\end{array}$ & $14,95^{* *}$ & $18,72^{* *}$ & $2,98 * *$ & $18,39 * *$ & $2,92 * *$ & 7,59 \\
\hline $\begin{array}{l}5 / 8 \mathrm{C} 3 / 8 \mathrm{~N} \\
5 / 8 \mathrm{~N} 3 / 8 \mathrm{C} \\
\text { Média G3 }\end{array}$ & $\begin{array}{l}438,5 \pm 15,2 \\
452,7 \pm 13,2 \\
445,6 \pm 10,01\end{array}$ & $\begin{array}{l}252,2 \pm 9,7 \\
257,1 \pm 8,4 \\
254,7 \pm 6,4\end{array}$ & $\begin{array}{l}57,5 \pm 0,5 \\
56,7 \pm 0,4 \\
57,1 \pm 0,3\end{array}$ & $\begin{array}{l}246,7 \pm 9,6 \\
251,7 \pm 8,3 \\
249,2 \pm 6,3\end{array}$ & $\begin{array}{l}56,2 \pm 0,5 \\
55,5 \pm 0,4 \\
55,9 \pm 0,3\end{array}$ & $\begin{array}{l}2,2 \pm 0,2 \\
2,1 \pm 0,1 \\
2,1 \pm 0,1\end{array}$ \\
\hline $\begin{array}{l}\text { G3 mean } \\
\text { Heterose G3, \% }\end{array}$ & $19,98^{* *}$ & $24,16^{* *}$ & $3,14 * *$ & $24,59^{* *}$ & $3,74 * *$ & $-16,73^{* *}$ \\
\hline $\begin{array}{l}\text { G3 heterosis, \% } \\
11 / 16 \text { C 5/16 N } \\
11 / 16 \text { N 5/16 C } \\
\text { Média G4 }\end{array}$ & $\begin{array}{l}471,7 \pm 16,8^{\mathrm{a}} \\
407,6 \pm 20,3^{\mathrm{b}} \\
439,6 \pm 13,5\end{array}$ & $\begin{array}{l}268,5 \pm 10,7^{\mathrm{a}} \\
234,2 \pm 12,9^{\mathrm{b}} \\
251,4 \pm 8,6\end{array}$ & $\begin{array}{l}56,8 \pm 0,6 \\
57,4 \pm 0,8 \\
57,1 \pm 0,5\end{array}$ & $\begin{array}{l}262,8 \pm 10,5^{\mathrm{a}} \\
228,7 \pm 12,8^{\mathrm{b}} \\
245,8 \pm 8,5\end{array}$ & $\begin{array}{l}55,6 \pm 0,6 \\
56,1 \pm 0,6 \\
55,8 \pm 0,5\end{array}$ & $\begin{array}{l}2,1 \pm 0,2 \\
2,4 \pm 0,2 \\
2,2 \pm 0,1\end{array}$ \\
\hline $\begin{array}{l}\text { G4 mean, } \% \\
\text { Heterose } \mathrm{G} 4, \% \\
\text { G4 heterosis, \% }\end{array}$ & $18,38^{* *}$ & $22,55^{* *}$ & $3,22 * *$ & $22,88^{* *}$ & $3,71 * *$ & $-12,84 *$ \\
\hline $\begin{array}{l}\text { Heterose retida, } \% \\
\text { Retained heterosis, \% }\end{array}$ & $18,29^{* *}$ & $22,21 * *$ & $3,22 * *$ & $22,46^{* *}$ & $3,45 * *$ & $-7,33$ \\
\hline $\begin{array}{l}\text { Diferença de mestiços e C, } \% \\
\text { Crossbreds and C difference, \% }\end{array}$ & $5,47 * * *$ & $9,51 * *$ & $4,63 * *$ & $9,77 * *$ & $4,98 * *$ & $-11,69$ \\
\hline $\begin{array}{l}\text { Diferença de mestiços e N, \% } \\
\text { Crossbreds and N difference, \% }\end{array}$ & $25,73 * * *$ & $26,80 * * *$ & 1,60 & $26,91 * * *$ & 1,67 & $-4,13$ \\
\hline
\end{tabular}

${ }^{* * *} \mathrm{P}<0,01 ;{ }^{* *} \mathrm{P}<0,05 ;{ }^{*} \mathrm{P}<0,10 .\left({ }^{* * *} P<.01 ;{ }^{* *} P<.05 ;{ }^{*} P<.10\right)$

Médias, na coluna, seguidas por letras diferentes, na comparação entre $\mathrm{C}$ e $\mathrm{N}$, ou entre os genótipos dentro da mesma geração de cruzamento, são diferentes $(P<0,05)$ pelo teste $T$.

Means, within a column, followed by different letters for the comparison between $C$ and $N$, or between genotypes within the same crossbreeding generation, are different $(P<.05)$ by $t$ test.

descarte terminadas em confinamento, houve superioridade da raça Charolês no peso de carcaça quente (8\%), com 9,41\% de heterose nas vacas F1 (Restle et al., 2002). Estes resultados evidenciam o elevado valor genético aditivo do genótipo Charolês para taxa de crescimento e peso adulto, que é incorporado aos genótipos mestiços. Portanto, esta raça é indicada nos cruzamentos para aumentar o peso de carcaça, como também foi relatado no trabalho de Peacock et al. (1979), que verificaram, em novilhos abatidos com cerca de 14 meses de idade, que o peso da carcaça de novilhos Charolês $(257,7 \mathrm{~kg}$ ) foi superior ao dos Brahman (207,3 kg), representando 24\%, como neste estudo, e, ao dos Aberdeen Angus (196,4 kg), sendo que o cruzamento recíproco do Charolês com estas duas raças resultou em mestiços com carcaças 23 e $22 \%$ mais pesadas que a dos genótipos puros, respectivamente.

As heteroses para os rendimentos de carcaça quente e fria foram significativas em todas as gerações do cruzamento, sendo a heterose retida 3,22 e $3,45 \%$, respectivamente, indicando que os animais mestiços foram superiores aos puros nestas características. Long (1980) comenta que os níveis de heterose para rendimento de carcaça oscilam em torno de $1 \%$, mas vários trabalhos na literatura nacional comprovam que maiores níveis de heterose nos cruzamentos 
que envolvem Charolês e Nelore - Restle et al. (1995a) (2,86\%); Restle et al. (2000) (3,08\%); e Restle et al. (2002) (2,35\%).

$\mathrm{O}$ rendimento de carcaça tornou-se muito importante nos últimos anos para o sistema de produção. Inicialmente os bovinos eram comercializados com base no peso vivo, mas gradativamente a comercialização passou a ser efetuada com base no peso de carcaça, principalmente carcaça quente. Nesta característica, o Nelore se sobressaiu, conforme pode ser verificado na comparação com o Charolês. Os novilhos Nelore apresentaram menores $(\mathrm{P}<0,05)$ pesos relativos do trato gastrintestinal $(7,0$ vs $5,2 \mathrm{~kg} / 100 \mathrm{~kg}$ de peso de corpo vazio) e das patas ( 2,18 vs $1,88 \mathrm{~kg})$ e absolutos do conjunto dos órgãos internos (15,3 vs $10,5 \mathrm{~kg})$, além de menor valor numérico do conteúdo do trato gastrintestinal $(11,36$ vs $10,75 \mathrm{~kg}$ ), resultando em maior rendimento de carcaça. Esta superioridade do genótipo Nelore foi incorporada nos genótipos mestiços, conforme tam- bém foi observado por Restle et al. (1999), que constataram relação linear crescente para rendimento de carcaça, com o aumento da participação de genes Nelore nos genótipos produzidos pelo cruzamento com o Hereford.

A quebra ao resfriamento reflete a perda de peso que a carcaça sofre durante o processo de resfriamento nas primeiras 24 horas após o abate e apresentou heterose negativa na G3 e na G4, indicando que as carcaças dos novilhos destas gerações de cruzamento perderam menos água. Nesta característica, que tem grande importância para os frigoríficos, é desejável a heterose negativa, também constatada por Restle et al. (1995a) $(-9,42 \%)$ na G1 e Restle et al. (2000) na G1 $(-18,61 \%)$ e G2 $(-30,30 \%)$ do cruzamento entre Charolês e Nelore. Segundo Müller (1987), a espessura de gordura que recobre a carcaça reduz as perdas por desidratação durante o resfriamento, o que foi confirmado no trabalho de Perobelli et al. (1995).

Tabela 2 - Médias, erros-padrão e heterose para maturidade fisiológica (MATF), espessura de gordura subcutânea (EG) e EG por $100 \mathrm{~kg}$ de carcaça de novilhos, de acordo com geração de cruzamento e grupo genético

Table 2 - Means, standard errors and heterosis for physiologic maturity (MATF), fat thickness (EG) and EG per $100 \mathrm{~kg}$ of carcass of steers, according to crossbreeding generation and genetic group

\begin{tabular}{|c|c|c|c|}
\hline $\begin{array}{l}\text { Grupo genético } \\
\text { Genetic group }\end{array}$ & MATF, pontos ${ }^{1}$ & $\mathrm{EG}, \mathrm{mm}$ & $\mathrm{EG} 100, \mathrm{~mm}$ \\
\hline Charolês (C) & $14,0 \pm 0,2^{\mathrm{a}}$ & $4,8 \pm 0,6^{\mathrm{a}}$ & $2,2 \pm 02$ \\
\hline Charolais $(C)$ & & & \\
\hline Nelore (N) & $13,4 \pm 0,1^{b}$ & $3,6 \pm 0,4^{\mathrm{b}}$ & $2,0 \pm 0,2$ \\
\hline Nellore (N) & & & \\
\hline Média puros (Straightbreds mean) & $13,7 \pm 0,1$ & $4,2 \pm 0,4$ & $2,1 \pm 0,1$ \\
\hline $3 / 4 \mathrm{C}^{1 / 4} \mathrm{~N}$ & $13,7 \pm 0,2$ & $4,4 \pm 0,6$ & $1,9 \pm 0,2$ \\
\hline $3 / 4 \mathrm{~N} 1 / 4 \mathrm{C}$ & $13,6 \pm 0,2$ & $4,9 \pm 0,5$ & $2,1 \pm 0,2$ \\
\hline Média G2 (G2 mean) & $13,6 \pm 0,2$ & $4,7 \pm 0,4$ & $2,0 \pm 0,2$ \\
\hline Heterose G2, \% (G2 heterosis, \%) & $-0,58$ & 10,71 & $-5,98$ \\
\hline $5 / 8 \mathrm{C} 3 / 8 \mathrm{~N}$ & $13,6 \pm 0,1^{\mathrm{a}}$ & $3,9 \pm 0,4$ & $1,6 \pm 0,2$ \\
\hline $5 / 8 \mathrm{~N} 3 / 8 \mathrm{C}$ & $13,3 \pm 0,1^{b}$ & $4,9 \pm 0,4$ & $1,9 \pm 0,1$ \\
\hline Média G3 (G3 mean) & $13,5 \pm 0,1$ & $4,4 \pm 0,3$ & $1,8 \pm 0,1$ \\
\hline Heterose G3, \% (G3 heterosis, \%) & $-1,75^{*}$ & 5,00 & $-14,83$ \\
\hline $11 / 16 \mathrm{C} 5 / 16 \mathrm{~N}$ & $13,1 \pm 0,1$ & $5,9 \pm 0,6$ & $2,2 \pm 0,2$ \\
\hline $11 / 16 \mathrm{~N} 5 / 16 \mathrm{C}$ & $13,0 \pm 0,2$ & $5,5 \pm 0,7$ & $2,4 \pm 0,3$ \\
\hline Média G4 (G4 mean) & $13,0 \pm 0,1$ & $5,7 \pm 0,5$ & $2,3 \pm 0,2$ \\
\hline Heterose G4, \% (G4 heterosis, \%) & $-4,89 * *$ & $35,95 * *$ & 11,48 \\
\hline Heterose retida, \% (Retained heterosis, \%) & $-2,41 * *$ & 17,22 & $-3,11$ \\
\hline Diferença de mestiços e C, \% (Crossbreds and C difference, \%) & ) $-4,68 * *$ & 3,32 & $-6,67$ \\
\hline Diferença de mestiços e N, \% (Crossbreds and $N$ difference, \%) & $-0,26$ & $26,07 * * *$ & 0,25 \\
\hline
\end{tabular}

${ }^{* * *} \mathrm{P}<0,01 ;{ }^{* *} \mathrm{P}<0,05 ;{ }^{*} \mathrm{P}<0,10 \quad\left({ }^{* * *} \mathrm{P}<.01 ;{ }^{* *} \mathrm{P}<.05 ;{ }^{*} \mathrm{P}<.10\right)$.

Médias, na coluna, seguidas por letras diferentes, na comparação entre $\mathrm{C}$ e $\mathrm{N}$, ou entre os genótipos, dentro da mesma geração de cruzamento, são diferentes $(\mathrm{P}<0,05)$ pelo teste $t$.

Means, within a column, followed by different letters for the comparison between $C$ and $N$, or between genotypes, within the same crossbreeding generation, are different $(P<.05)$ by $t$ test.

${ }^{2}$ Escala de 1 a 15 pontos, sendo menor valor, maturidade mais avançada.

2 Scale from 1 to 15 points, being lower value, more advanced maturity. 
As médias e a heterose para maturidade fisiológica e espessura de gordura subcutânea, em mm e ajustada para $100 \mathrm{~kg}$ de carcaça fria, estão expressas na Tabela 2.

Para maturidade fisiológica da carcaça, a heterose foi negativa e significativa na G3 e G4. Verifica-se, ainda, diferença entre os animais puros, sendo que os Nelore apresentaram menor pontuação. Isso indica que, nestes grupos genéticos, a ossificação das cartilagens dos processos espinhosos das vértebras torácicas e o grau de fusão das vértebras sacrais são maiores, indicando estádio de desenvolvimento fisiológico mais avançado. No entanto, Vaz (1999), em seu estudo, não constatou diferença na maturidade fisiológica das carcaças de animais Nelore e Charolês, nem heterose significativa na G1 e G2, embora tenha sido negativa.

A espessura de gordura subcutânea, atributo importante da carcaça, em todos grupos genéticos, situou-se entre 3 e $6 \mathrm{~mm}$, que é a faixa que os frigoríficos consideram adequada. Verifica-se que, entre os animais puros, a espessura de gordura foi significativamente maior nos Charolês, o que não era esperado, pois todos os trabalhos em que animais destas duas raças são comparados na mesma faixa etária reportam maior espessura de gordura para o Nelore, tanto em novilhos (Restle et al., 1995a; Moletta \& Restle, 1996; Vaz, 1999; Restle et al., 2000), como em vacas (Perobelli et al., 1995; Restle et al., 2002). Possíveis explicações para este comportamento são o baixo peso de abate e de carcaça dos animais Nelore, pois a correlação entre peso de carcaça e espessura de gordura foi de $0,55(\mathrm{P}<0,05)$ (Tabela 6), o que foi reforçado ao ajustar a espessura de gordura para $100 \mathrm{~kg}$ de carcaça, quando a diferença entre os grupos genéticos deixou de existir. Outro aspecto que deve ter contribuído para a maior deposição de gordura subcutânea no Charolês foi a densidade energética da dieta e o elevado ganho de peso médio destes animais. Segundo Menezes (2004), o ganho de peso médio diário dos animais foi de $1,46 \mathrm{~kg}$ (Charolês) vs $0,98 \mathrm{~kg}$ (Nelore). Este desempenho fez com que o estado corporal que, no início do confinamento, foi maior para o Nelore, passasse a ser maior para o Charolês no final do período de confinamento. Uma vez atendidas as exigências de mantença, crescimento dos órgãos e dos tecidos, o excedente de energia consumida é depositado sob a forma de gordura. Segundo o NRC (1996), a deposição de gordura nos animais depende, além do grupo genético, do peso vivo do animal, da intensidade do ganho de peso diário, da maturidade e da densidade energética da dieta.

A heterose para espessura de gordura foi positiva nas três gerações de cruzamento. No entanto, foi significativa apenas na G4. Níveis elevados de heterose para esta característica, em novilhos terminados aos 24 meses, são relatados por Vaz (1999) e Restle et al. (2000) para a G1 e G2 do cruzamento rotativo entre Charolês e Nelore. Utilizando vacas de descarte do mesmo rebanho, terminadas em confinamento, Restle et al. (2002) também observaram, na G1, elevado nível de heterose para espessura de gordura nesta categoria. Segundo Gregory et al. (1994), a característica que apresenta maior diversidade entre raças é a deposição de gordura, resultando em altos níveis de heterose (Slanger et al., 1985; Urick et al., 1989).

Constam na Tabela 3 as médias das características relacionadas ao desenvolvimento muscular da carcaça.

A heterose para conformação, que é a avaliação subjetiva da musculosidade da carcaça, foi significativa nas três gerações de cruzamento, sendo a heterose retida de $8,09 \%$. A conformação da carcaça do Charolês foi superior à do Nelore e muito similar à dos mestiços, com predominância do Charolês no genótipo. Nas três gerações de cruzamento, a conformação foi melhor nas carcaças dos animais com predominância do genótipo Charolês que naqueles com predominância de Nelore, sendo a diferença significativa na G2 e na G4. Conformação é uma característica influenciada positivamente pelo peso de abate e, conseqüentemente, pelo peso da carcaça, como neste experimento, em que a correlação, envolvendo todos os animais, entre conformação e peso de carcaça foi de 0,68 $(\mathrm{P}<0,05)$ (Tabela 6). Esta constatação poderia levar a uma conclusão errônea de que o Charolês apresentou melhor conformação que o Nelore, apenas pelo fato de ter apresentado maior peso de carcaça. No entanto, ao analisar a conformação dos animais da G2, observa-se que esta foi melhor nos animais $3 / 4 \mathrm{C} 1 / 4 \mathrm{~N}$ que nos $3 / 4 \mathrm{~N} 1 / 4 \mathrm{C}$, embora o peso de carcaça dos dois genótipos tenha sido similar. Estes resultados evidenciam a importância desta raça para proporcionar musculosidade à carcaça.

A área do músculo Longissimus dorsi (AOL), que é o meio mais utilizado pelos pesquisadores para medir objetivamente a musculosidade da carcaça, apresentou correlação de 0,58 com a conformação, além de valores altos de heterose, indicando que o cruzamento melhorou esta característica, sendo a heterose retida de $11,33 \%$. Quando a AOL foi ex- 
Tabela 3 - Médias, erros-padrão e heterose para conformação (CONF), área do músculo Longissimus dorsi (AOL), AOL por $100 \mathrm{~kg}$ de carcaça fria (AOL100), espessura de coxão (ECOX) e perímetro de braço (PBR) de novilhos, de acordo com geração de cruzamento e grupo genético

Table 3 - Means, standard errors and heterosis for conformation (CONF), "Longissimus dorsi" muscle area (AOL), AOL per $100 \mathrm{~kg}$ of cold carcass (AOL100), cushion thickness (ECOX) and arm perimeter (PBR) of steers, according to crossbreeding generation and genetic group

\begin{tabular}{|c|c|c|c|c|c|}
\hline $\begin{array}{l}\text { Grupo genético } \\
\text { Genetic group }\end{array}$ & CONF, pontos ${ }^{1}$ & $\mathrm{AOL}, \mathrm{cm}^{2}$ & AOL100, $\mathrm{cm}^{2}$ & $\mathrm{ECOX}, \mathrm{cm}$ & PBR, $\mathrm{cm}$ \\
\hline$\overline{\text { Charolês (C) }}$ & $11,8 \pm 0,4^{\mathrm{a}}$ & $67,3 \pm 4,3^{\mathrm{a}}$ & $30,2 \pm 1,6$ & $24,3 \pm 0,7^{\mathrm{a}}$ & $37,2 \pm 1,2^{\mathrm{a}}$ \\
\hline \multicolumn{6}{|l|}{ Charolais $(C)$} \\
\hline Nelore (N) & $9,1 \pm 0,2^{b}$ & $52,1 \pm 2,7^{b}$ & $28,7 \pm 1,0$ & $21,1 \pm 0,5^{\mathrm{b}}$ & $32,5 \pm 0,8^{b}$ \\
\hline \multicolumn{6}{|l|}{ Nellore $(N)$} \\
\hline \multirow{2}{*}{\multicolumn{6}{|c|}{ Straightbreds mean }} \\
\hline & & & & & \\
\hline $3 / 4 \mathrm{C}^{1 / 4} \mathrm{~N}$ & $11,8 \pm 0,4^{\mathrm{a}}$ & $68,7 \pm 4,3$ & $28,4 \pm 1,5^{\mathrm{a}}$ & $23,8 \pm 0,7$ & $36,8 \pm 1,2$ \\
\hline $3 / 4 \mathrm{~N}^{1 / 4} \mathrm{C}$ & $10,7 \pm 0,3^{b}$ & $59,1 \pm 3,5$ & $24,1 \pm 1,3^{b}$ & $23,5 \pm 0,6$ & $36,5 \pm 1,0$ \\
\hline Média G2 & $11,3 \pm 0,2$ & $63,9 \pm 2,8$ & $26,3 \pm 1,0$ & $23,7 \pm 0,5$ & $36,6 \pm 0,8$ \\
\hline \multicolumn{6}{|l|}{ G2 mean } \\
\hline Heterose G2, \% & $7,81 * *$ & 7,04 & $-10,64 * *$ & 4,50 & 5,09 \\
\hline \multicolumn{6}{|l|}{ G2 heterosis, \% } \\
\hline $5 / 8 \mathrm{C} 3 / 8 \mathrm{~N}$ & $11,5 \pm 0,3$ & $66,8 \pm 3,2$ & $26,9 \pm 1,3$ & $23,9 \pm 0,6$ & $36,9 \pm 0,8$ \\
\hline $5 / 8 \mathrm{~N} 3 / 8 \mathrm{C}$ & $10,9 \pm 0,2$ & $68,1 \pm 2,7$ & $26,6 \pm 1,1$ & $25,0 \pm 0,6$ & $36,8 \pm 0,7$ \\
\hline Média G3 & $11,2 \pm 0,2$ & $67,5 \pm 2,1$ & $26,8 \pm 0,8$ & $24,5 \pm 0,4$ & $36,9 \pm 0,5$ \\
\hline \multicolumn{6}{|l|}{ G3 mean } \\
\hline Heterose G3, \% & $7,66^{* *}$ & $13,02 * *$ & $-9,01 * *$ & $7,92 * *$ & $5,72 * *$ \\
\hline \multicolumn{6}{|l|}{ G3 heterosis, \% } \\
\hline $11 / 16 \mathrm{C} 5 / 16 \mathrm{~N}$ & $11,8 \pm 0,3^{\mathrm{a}}$ & $73,4 \pm 3,8$ & $27,8 \pm 1,5$ & $25,2 \pm 0,5$ & $38,3 \pm 1,1$ \\
\hline $11 / 16 \mathrm{~N} 5 / 16 \mathrm{C}$ & $10,9 \pm 0,3^{b}$ & $62,6 \pm 4,5$ & $26,9 \pm 1,9$ & $24,6 \pm 0,6$ & $36,4 \pm 1,3$ \\
\hline Média G4 & $11,4 \pm 0,2$ & $68,0 \pm 3,0$ & $27,3 \pm 1,2$ & $24,9 \pm 0,4$ & $37,3 \pm 0,9$ \\
\hline \multicolumn{6}{|l|}{ G4 mean } \\
\hline $\begin{array}{l}\text { Heterose G4, \% } \\
\text { G4 heterosis }\end{array}$ & $8,81 * *$ & $13,92 *$ & $-7,04$ & $9,93^{* *}$ & $7,03 * *$ \\
\hline Heterose retida, \% & $8,09 * * *$ & $11,33 * * *$ & $-8,90 * * *$ & $7,45^{* * *}$ & $5,95 * * *$ \\
\hline Retained heterosis, \% & & & & & \\
\hline $\begin{array}{l}\text { Diferença de mestiços e C, } \% \\
\text { Crossbreds and C difference, \% }\end{array}$ & $-4,74 * *$ & $-1,26^{* *}$ & $-12,51$ & $0,34 * *$ & $-0,74 * *$ \\
\hline $\begin{array}{l}\text { Diferença de mestiços e N, \% } \\
\text { Crossbreds and } N \text { difference, \% }\end{array}$ & $19,72^{* *}$ & 21,61 & $-7,02$ & $13,53^{* *}$ & $11,96^{* *}$ \\
\hline
\end{tabular}

${ }^{* * *} \mathrm{P}<0,01 ;{ }^{* *} \mathrm{P}<0,05 ; \quad{ }^{*} \mathrm{P}<0,10 .\left({ }^{* *} P<.01 ;{ }^{* *} P<.05 ;{ }^{*} P<.10\right)$

Médias, na coluna, seguidas por letras diferentes, na comparação entre $\mathrm{C}$ e $\mathrm{N}$, ou entre os genótipos dentro da mesma geração de cruzamento, são diferentes $(P<0,05)$ pelo teste t.

Means, within a column, followed by different letters for the comparison between $C$ and $\mathrm{N}$, or between genotypes within the same crossbreeding generation, are different $(P<.05)$ by $t$ test.

${ }^{1}$ Variação de 1 a 18 , sendo $7-9=$ regular, $10-12=$ boa.

${ }^{1}$ Variation from 1 to 18 , being: $7-9=$ regular; $10-12=$ good.

pressa por $100 \mathrm{~kg}$ de carcaça (AOL100), a heterose passou a ser negativa, como também foi constatado por Peacock et al. (1979) e Vaz (1999). Segundo Peacock et al (1979), para AOL100, é esperado que a heterose seja negativa, pelo fato de o peso das carcaças dos mestiços ser mais elevado que o das raças puras e pela tendência de carcaças mais pesadas estarem associadas a menores valores para a relação entre AOL e peso de carcaça.

A AOL foi $29 \%$ maior no Charolês que no Nelore e parte desta diferença se deve ao maior peso da carcaça, pois, ao expressar a AOL por $100 \mathrm{~kg}$ de carcaça esta diferença decresceu para 5\%. Nos genótipos da G2 com predominância de Charolês, a AOL100 foi significativamente maior. Em pesquisas sobre cruzamento incluindo o Charolês, as constatações são unânimes sobre o efeito genético aditivo desta raça nas características relacionadas ao desenvolvimento muscular, tanto em novilhos (Peacock et al., 1979; DeRouen et al., 1992; Hickok et al., 1994, Restle et al., 1995b; Vaz, 1999; Perotto et al., 2000; Restle et al., 2000), como em vacas de descarte (Restle et al., 2002).

A espessura de coxão e o perímetro de braço também são características relacionadas à 
Tabela 4 Médias, erros-padrão e heterose para comprimento de carcaça (CCARC), de perna (CPER) e de braço (CBR) da carcaça de novilhos, de acordo com geração de cruzamento e grupo genético

Table 4 - Means, standard errors and heterosis for carcass length (CCARC), leg length (CPER) and arm length (CBR) of the carcass of steers, according to crossbreeding generation and genetic group

\begin{tabular}{llll}
\hline $\begin{array}{l}\text { Grupo genético } \\
\text { Genetic group }\end{array}$ & CCARC,cm & CPER, cm & CBR, cm \\
\hline Charolês (C) & $119,0 \pm 4,6^{\mathrm{a}}$ & $64,5 \pm 1,5^{\mathrm{b}}$ & $38,0 \pm 0,7^{\mathrm{b}}$ \\
Charolais $(C)$ & $108,1 \pm 2,8^{\mathrm{b}}$ & $68,4 \pm 1,0^{\mathrm{a}}$ & $40,0 \pm 0,5^{\mathrm{a}}$ \\
Nelore (N) & & & \\
Nellore $(N)$ & $113,5 \pm 2,7$ & $66,4 \pm 0,9$ & $39,0 \pm 0,4$ \\
Média puros (Straightbreds mean) & $131,1 \pm 4,6$ & $67,3 \pm 1,5^{\mathrm{b}}$ & $39,2 \pm 0,7^{\mathrm{b}}$ \\
3/4C 1/4N & $122,2 \pm 3,7$ & $72,9 \pm 1,3^{\mathrm{a}}$ & $41,9 \pm 0,6^{\mathrm{a}}$ \\
3/4N 1/4C & $126,6 \pm 2,9$ & $70,1 \pm 1,0$ & $40,6 \pm 0,5$ \\
Média G2 (G2 mean) & $11,54^{* *}$ & $5,52^{* *}$ & $3,96^{* *}$ \\
Heterose G2, \% (G2 heterosis, \%) & $121,1 \pm 1,7$ & $69,5 \pm 1,0$ & $40,2 \pm 0,4^{\mathrm{b}}$ \\
5/8C 3/8N & $122,3 \pm 1,4$ & $71,1 \pm 0,9$ & $42,3 \pm 0,3^{\mathrm{a}}$ \\
5/8N 3/8C & $121,7 \pm 1,1$ & $70,3 \pm 0,7$ & $41,3 \pm 0,3$ \\
Média G3 (G3 mean) & $7,20^{* *}$ & $5,82^{* *}$ & $5,74^{* *}$ \\
Heterose G3, \% (G3 heterosis, \%) & $123,5 \pm 2,0$ & $70,3 \pm 1,1$ & $41,0 \pm 0,5$ \\
11/16C 5/16N & $119,3 \pm 2,4$ & $70,3 \pm 1,3$ & $41,2 \pm 0,6$ \\
11/16N 5/16C & $121,4 \pm, 6$ & $70,3 \pm 0,8$ & $41,1 \pm 0,4$ \\
Média G4 (G4 mean) & $6,92^{* *}$ & $5,83^{* *}$ & $5,28^{* *}$ \\
Heterose G4, \% (G4 heterosis, \%) & $8,55^{* *}$ & $5,73^{* *}$ & $4,99^{* *}$ \\
Heterose retida, \% (Retained heterosis, \%) & $3,49^{* * *}$ & $8,19 * *$ & $7,18^{* *}$ \\
Diferença de mestiços e C, \% (Crossbreds and C difference, \%) & $12,27^{* * *}$ & 2,64 & $2,33^{* *}$ \\
Diferença de mestiços e N, \% (Crossbreds and N difference, \%) & & & \\
\hline
\end{tabular}

${ }^{* \star *} \mathrm{P}<0,01 ;{ }^{* *} \mathrm{P}<0,05 ; \quad{ }^{*} \mathrm{P}<0,1 .\left({ }^{* * *} P<.01 ;{ }^{* *} P<.05 ;{ }^{*} P<.10\right)$.

Médias, na coluna, seguidas por letras diferentes, na comparação entre $C$ e $N$, ou entre os genótipos dentro da mesma geração de cruzamento, são diferentes $(\mathrm{P}<0,05)$ pelo teste $\mathrm{t}$.

Means, within a column, followed by different letters for the comparison between $C$ and $N$, or between genotypes within the same crossbreeding generation, are different $(P<.05)$ by $t$ test.

musculosidade e apresentaram comportamento da heterose similar à AOL, sendo a heterose retida de 7,45 e $5,95 \%$, respectivamente.

$\mathrm{Na}$ Tabela 4, são apresentados os resultados referentes às medidas de desenvolvimento da carcaça dos novilhos.

Os mestiços de todas as gerações de cruzamento foram superiores $(\mathrm{P}<0,05)$ aos animais puros para comprimento de carcaça, de perna e de braço, resultando em valores expressivos para heterose, seguindo a mesma tendência do peso de carcaça. Estes resultados corroboram a afirmação de Cundiff (1970) de que os níveis de heterose são elevados para características associadas ao crescimento.

$\mathrm{Na}$ literatura, em geral, são citados valores de heterose inferiores aos verificados neste estudo para características métricas da carcaça e variam de 2,8 (Arthur et al., 1989) a 3,77\% (Restle et al., 1995a), para comprimento de carcaça, de 2,5 (Restle et al., 1995a) a 4,09\% (Vaz \& Restle, 2001), para comprimento de perna, e de 2,33 (Restle et al., 1995a) a 2,7\% (Vaz \& Restle, 2001), para comprimento de braço.
Na comparação dos genótipos dentro dos sistemas de acasalamento, observou-se que os novilhos Charolês apresentaram maior comprimento de carcaça, enquanto os Nelore mostraram pernas e braços mais longos. Estes resultados estão de acordo com os citados por Moletta \& Restle (1996), Restle et al. (2000) e Vaz \& Restle (2001). Avaliando as carcaças de genótipos Nelore x Hereford, Restle et al. (1999) verificaram que o incremento de genes Nelore no cruzamento aumentou o comprimento dos membros e diminuiu o comprimento de carcaça, destacando as diferenças morfológicas entre as raças Bos taurus e Bos indicus e o efeito genético aditivo das duas raças como responsáveis pela variação.

Os pesos absolutos e os valores percentuais dos cortes comerciais da carcaça encontram-se na Tabela 5.

Não houve efeito $(\mathrm{P}>0,05)$ da heterozigose nas diferentes gerações de cruzamento sobre a percentagem dos cortes comerciais. Os percentuais da heterose para a composição percentual dos cortes comerciais foram baixos. Vaz (1999) infere que as características de carcaça expressas de forma percentual, por 
Tabela 5 - Média, erros-padrão e heterose para peso e percentagem de dianteiro (Diant), costilhar (Cost) e traseiro (Tras) da carcaça de novilhos, de acordo com geração de cruzamento e grupo genético

Table 5 - Mean, standard errors and heterosis for weight and percentage of forequarter (Diant), sidecut (Cost) and sawcut (Tras) of the carcass of steers, according to crossbreeding generation and genetic group

\begin{tabular}{|c|c|c|c|c|c|c|}
\hline $\begin{array}{l}\text { Grupo genético } \\
\text { Genetic group }\end{array}$ & Diant, kg & Cost, kg & Tras, kg & Diant, $\%$ & Cost, $\%$ & Tras, $\%$ \\
\hline Charolês (C) & $78,8 \pm 5,0^{\mathrm{a}}$ & $27,9 \pm 1,7^{\mathrm{a}}$ & $113,7 \pm 7,0^{\mathrm{a}}$ & $35,8 \pm 0,6^{b}$ & $12,7 \pm 0,3^{\mathrm{a}}$ & $51,7 \pm 0,5$ \\
\hline $\begin{array}{l}\text { Charolais }(C) \\
\text { Nelore }(\mathrm{N}) \\
\text { Nellore }(N)\end{array}$ & $66,6 \pm 3,2^{\mathrm{b}}$ & $20,3 \pm 1,1^{b}$ & $90,2 \pm 4,4^{b}$ & $37,4 \pm 0,4^{\mathrm{a}}$ & $11,5 \pm 0,2^{\mathrm{b}}$ & $50,5 \pm 0,3$ \\
\hline $\begin{array}{l}\text { Média puros } \\
\text { Straightbreds mean }\end{array}$ & $72,7 \pm 3,0$ & $24,1 \pm 1,0$ & $101,9 \pm 4,1$ & $36,6 \pm 0,3$ & $12,1 \pm 0,2$ & $51,1 \pm 0,3$ \\
\hline $\begin{array}{r}3 / 4 \mathrm{C}^{1 / 4 \mathrm{~N}} \\
3 / 4 \mathrm{~N}^{1 / 4 \mathrm{C}} \\
\text { Média } \mathrm{G} 2\end{array}$ & $\begin{array}{l}88,4 \pm 5,0 \\
87,9 \pm 4,1 \\
88,2 \pm 3,2\end{array}$ & $\begin{array}{l}27,3 \pm 1,7 \\
28,3 \pm 1,4 \\
27,8 \pm 1,1\end{array}$ & $\begin{array}{l}119,5 \pm 6,7 \\
123,5 \pm 5,7 \\
121,5 \pm 4,5\end{array}$ & $\begin{array}{l}37,8 \pm 0,6 \\
36,7 \pm 0,5 \\
37,3 \pm 0,5\end{array}$ & $\begin{array}{l}11,6 \pm 0,3 \\
11,8 \pm 0,3 \\
11,7 \pm 0,2\end{array}$ & $\begin{array}{l}51,2 \pm 0,5 \\
51,5 \pm 0,4 \\
51,3 \pm 0,3\end{array}$ \\
\hline $\begin{array}{l}\text { G2 mean } \\
\text { Heterose G2, \% }\end{array}$ & $21,26 * *$ & $15,29 * *$ & $19,19^{* *}$ & 1,76 & $-3,43$ & 0,48 \\
\hline $\begin{array}{l}\text { G2 heterosis, \% } \\
5 / 8 \mathrm{C} 3 / 8 \mathrm{~N} \\
5 / 8 \mathrm{~N} 3 / 8 \mathrm{C} \\
\text { Média G3 }\end{array}$ & $\begin{array}{l}92,4 \pm 4,3 \\
92,5 \pm 3,7 \\
92,4 \pm 2,9\end{array}$ & $\begin{array}{l}28,8 \pm 1,2 \\
31,8 \pm 1,1 \\
30,3 \pm 0,8\end{array}$ & $\begin{array}{l}125,8 \pm 5,1 \\
126,9 \pm 4,4 \\
126,3 \pm 3,4\end{array}$ & $\begin{array}{l}37,5 \pm 1,3 \\
36,8 \pm 1,2 \\
37,2 \pm 0,9\end{array}$ & $\begin{array}{l}11,7 \pm 0,3 \\
12,6 \pm 0,3 \\
12,2 \pm 0,2\end{array}$ & $\begin{array}{l}51,0 \pm 0,3 \\
50,4 \pm 0,3 \\
50,7 \pm 0,2\end{array}$ \\
\hline $\begin{array}{l}\text { G3 mean } \\
\text { Heterose G3, \% }\end{array}$ & $27,12 * *$ & $25,88^{* *}$ & $23,97 * *$ & 1,46 & 0,79 & $-0,82$ \\
\hline $\begin{array}{l}\text { G3 heterosis, \% } \\
11 / 16 \mathrm{C} 5 / 16 \mathrm{~N} \\
11 / 16 \mathrm{~N} 5 / 16 \mathrm{C} \\
\text { Média G4 }\end{array}$ & $\begin{array}{l}96,7 \pm 3,8^{\mathrm{a}} \\
84,0 \pm 4,6^{\mathrm{b}} \\
90,3 \pm 3,1\end{array}$ & $\begin{array}{l}31,4 \pm 1,4 \\
28,2 \pm 1,7 \\
29,8 \pm 1,1\end{array}$ & $\begin{array}{l}134,3 \pm 5,5^{\mathrm{a}} \\
113,6 \pm 6,7^{\mathrm{b}} \\
123,9 \pm 4,4\end{array}$ & $\begin{array}{l}36,8 \pm 0,4 \\
36,7 \pm 0,5 \\
36,7 \pm 0,3\end{array}$ & $\begin{array}{l}12,0 \pm 0,3 \\
12,3 \pm 0,3 \\
12,1 \pm 0,2\end{array}$ & $\begin{array}{l}51,2 \pm 0,6 \\
49,7 \pm 0,7 \\
50,4 \pm 0,5\end{array}$ \\
\hline $\begin{array}{l}\text { G4 mean } \\
\text { Heterose G4, \% } \\
\text { G4 heterosis }\end{array}$ & $24,27 * *$ & $23,80 * *$ & $21,61 * *$ & 0,36 & 0,37 & $-1,34$ \\
\hline $\begin{array}{l}\text { Heterose retida, \% } \\
\text { Retained heterosis, \% }\end{array}$ & $24,22 * *$ & $21,66^{* *}$ & $21,59 * *$ & 1,19 & $-0,76^{* *}$ & $-0,56$ \\
\hline $\begin{array}{l}\text { Diferença de mestiços e C, } \% \\
\text { Crossbreds and C difference, \% }\end{array}$ & 12,76 & $4,99 * * *$ & $8,26 * * *$ & 3,38 & $-5,68 * *$ & $-1,72$ \\
\hline $\begin{array}{l}\text { Diferença de mestiços e } \mathrm{N}, \% \\
\text { Crossbreds and } N \text { difference, } \%\end{array}$ & $26,23 * * *$ & $30,61 * * *$ & $27,26 * * *$ & $-1,02$ & 4,15 & 0,59 \\
\hline
\end{tabular}

${ }^{* * *} \mathrm{P}<0,01 ;{ }^{*} \mathrm{P}<0,05 ;{ }^{*} \mathrm{P}<0,10\left({ }^{* * *} P<.01 ;{ }^{* *} P<.05 ;{ }^{*} P<.10\right)$

Médias, na coluna, seguidas por letras diferentes, na comparação entre $\mathrm{C}$ e $\mathrm{N}$, ou entre os genótipos dentro da mesma geração de cruzamento, são diferentes $(\mathrm{P}<0,05)$ pelo teste $\mathrm{t}$.

Means, within a column, followed by different letters for the comparison between $C$ and $N$, or between genotypes within the same crossbreeding generation, are different $(P<.05)$ by $t$ test.

serem medidas complementares, não são as mais indicadas para expressar os valores de heterose quando se deseja quantificar estas características. Este autor também verificou valores de heterose próximos de zero quando analisou os cortes comerciais como porcentagem da carcaça de novilhos de duas gerações de cruzamento rotativo das raças Charolês e Nelore.

A heterose para peso dos três cortes comerciais foi significativa em todas as gerações de cruzamento, acompanhando a oscilação do grau de heterozigose, como ocorreu com o peso de carcaça. A heterose retida foi expressiva, sendo 24,22; 21,66 e 21,59\%, respectivamente, para os cortes dianteiro, costilhar ou ponta de agulha e traseiro.
Novilhos Charolês apresentaram, em todos os cortes, maior peso que os Nelore, o que era esperado, em razão do maior peso de carcaça. Quando os cortes foram expressos percentualmente, o Nelore apresentou maior porcentagem de dianteiro e o Charolês maior porcentagem de costilhar. A maior percentagem do corte dianteiro nos zebuínos devese, em parte, à presença do cupim (Luchiari Filho et al., 1985), enquanto o maior percentual de corte costilhar no Charolês é o resultado do maior arqueamento das costelas. Além disso, segundo Vaz (1999), a deposição de gordura nesta região aumenta o peso deste corte e, conseqüentemente, seu percentual na carcaça, o que leva a uma correlação significativa entre espessura de gordura e porcentagem de costilhar. 


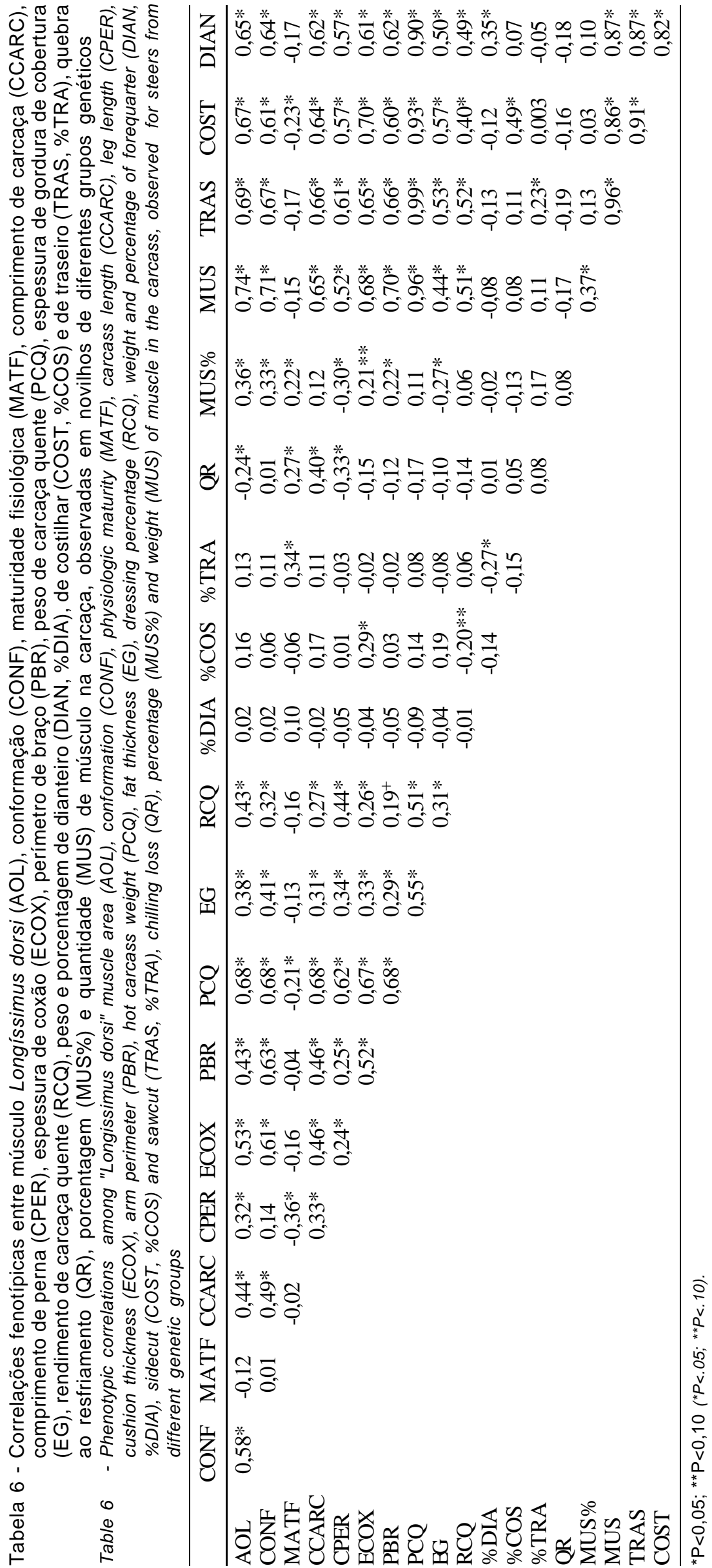


Neste trabalho, a correlação entre estas duas características, embora positiva, não foi significativa.

A análise de contrastes indicou que animais cruzados com maior predominância de sangue Charolês (CRC) apresentam maior peso de traseiro, o que é desejável, uma vez que os músculos mais valorizados do animal se encontram neste corte.

As correlações (Tabela 6) entre peso de carcaça e peso absoluto dos cortes dianteiro $(0,90)$, costilhar $(0,93)$ e traseiro $(0,99)$ foram significativas. No entanto, as correlações entre peso de carcaça e a percentagem dos cortes foram de baixa magnitude e não-significativas.

Para o sistema de produção, é importante a comparação do desempenho dos animais mestiços das gerações de cruzamento em relação ao das duas raças puras. $\mathrm{O}$ cruzamento produziu animais mestiços com maiores pesos de abate, de carcaças quente e fria, maior espessura de coxão, maiores comprimentos de carcaça e de braço e pesos de costilhar e de traseiro que qualquer uma das raças puras. Por outro lado, o cruzamento melhorou os rendimentos de carcaças quente e fria em relação ao Charolês puro, não afetando quando comparado ao Nelore. Estes resultados indicam que o cruzamento entre as raças Charolês e Nelore levam a produtos com carcaças de musculosidade semelhante às do Charolês e de rendimento semelhante às do Nelore.

\section{Conclusões}

O novilho Charolês é superior ao Nelore em pesos de abate e de carcaça e nas características relacionadas à musculosidade da carcaça, enquanto o Nelore é superior ao Charolês em rendimento de carcaça e em comprimento dos membros.

Os animais mestiços Charolês x Nelore apresentam maior peso de abate, maiores peso e rendimento de carcaça quente e fria e maior espessura de gordura de cobertura da carcaça, resultando em menor perda de líquidos durante o resfriamento que os animais puros.

As características relacionadas ao desenvolvimento corporal, comprimentos de carcaça, perna e braço e as relacionadas a musculosidade da carcaça, conformação, área do músculo Longissimus dorsi, espessura de coxão e perímetro de perna são melhoradas pelo cruzamento.

A proporção dos cortes comerciais na carcaça não é afetada pela heterozigose, mas, para os seus valores absolutos, a heterose é expressiva.

Animais mestiços apresentam maior grau de ossificação das cartilagens dos processos espinhosos das vértebras torácicas e maior grau de fusão das vértebras sacrais, indicando estádio de desenvolvimento fisiológico mais avançado.

\section{Literatura Citada}

ARTHUR, P.F.; MAKARECHIAN, M.; PRICE, M.A. et al. Heterosis, maternal and direct effects in double-muscled and normal cattle: II Carcass traits of young bulls. Journal of Animal Science, v.67, n.4, p.911-919, 1989.

CUNDIFF, L.V. Experimental results on crossbreeding cattle for beef production. Journal of Animal Science, v.30, n.3, p.694-705, 1970.

DeROUEN, S.M.; FRANKE, D.E.; BIDNER, T.D. et al. Direct and maternal genetic effects for carcass traits in beef cattle. Journal of Animal Science, v.70, n.12, p.3677-3685, 1992.

GREGORY, K.E.; CUNDIFF, L.V.; KOCH, R.M. et al. Breed effects, retained heterosis, and estimated of genetic and phenotypic parameters for carcass and meat traits of beef cattle. Journal of Animal Science, v.72, n.5, p.1174-1183, 1994.

HICKOK, D.T.; SCHALLES, R.R.; DIKEMAN, M.E. et al. Effects of different cattle crossbreed combinations on feedlot performance and carcass characteristics. Journal of Animal Science, v.72 (Supplement 1), n.1, p.150, 1994.

KOGER, M. Effective crossbreeding systems utilizing zebu cattle. Journal of Animal Science, v.50, n.6, p.1213-1220, 1980.

KOGER, M.; PEACOCK, F.M.; KIRK, W.G. et al. Heterosis effects on weaning performance of Brahman-Shorton calves. Journal of Animal Science, v.40, n.5, p.826-833, 1975.

LONG, C.R. Crossbreeding for beef production: experimental results. Journal of Animal Science, v.51, n.5, p.1197-1223, 1980

LUCHIARI FILHO, A.; BOIN, C.; ALLEONI, G.F. et al. Efeito do tipo de animal no rendimento da porção comestível da carcaça. I. Machos da raça Nelore vs mestiços zebu x europeu terminados a pasto. Boletim da Indústria Animal, v.42, n.2, p.143-148, 1985.

MENEZES, L.F.G. Avaliação de novilhos das gerações avançadas do cruzamento rotativo Charolês - Nelore. Santa Maria: Universidade Federal de Santa Maria, 2004. 150p. Dissertação (Mestrado em Zootecnia) - Universidade Federal de Santa Maria, 2004.

MOLETTA, J.L.; RESTLE, J. Características de carcaça de novilhos de diferentes grupos genéticos terminados em confinamento. Revista Brasileira de Zootecnia, v.25, n.5, p.876-888, 1996.

MÜLLER, L. Normas para avaliação de carcaças e concurso de carcaça de novilhos. 2.ed. Santa Maria: Universidade Federal de Santa Maria, 1987. 31p.

NATIONAL RESEARCH COUNCIL - NRC. Nutrient requirement of beef cattle. 7.ed. Washington, D.C.: 1996. 232p.

PEACOCK, F.M.; PALMER, A.Z.; CARPENTER, J.W. et al. Breed and heterosis effects on carcass characteristics of Angus, Brahman, Charolais and crossbred steers. Journal of Animal Science, v.49, n.2, p.391-397, 1979.

PEROBELli, Z.V.; RESTLE, J.; MÜLLER, L. Estudo das carcaças de vacas de descarte das raças Charolês e Nelore. Pesquisa Agropecuária Brasileira, v.30, n.3, p.409-412, 1995. 
PEROTTO, D.; MOLETTA, J.L.; CUBAS, A.C. Características da carcaça de bovinos Canchim e Aberdeen Angus e de seus cruzamentos recíprocos terminados em confinamento. Ciência Rural, v.29, n.2, p.331-338, 1999.

PEROTTO, D.; MOLETTA, J.L.; CUBAS, A.C. Características quantitativas da carcaça de bovinos Charolês, Caracu e cruzamentos recíproco terminados em confinamento. Revista Brasileira de Zootecnia, v.29, n.1, p.117-124, 2000.

RESTLE, J.; FELTEN, H.G.; VAZ, F.N. Efeito da raça e heterose para características quantitativas da carcaça de novilhos de 24 meses terminados em confinamento. In: REUNIÓN LATINOAMERICANA DE PRODUCCIÓN ANIMAL, 14., 1995, Mar del Plata. Memorias... Balcare: ALPA, 1995a. n.3-4, p.857-859.

RESTLE, J.; FELTEN, H.G.; VAZ, F.N. Efeito da raça e heterose para qualidade da carcaça e da carne de novilhos terminados em confinamento. In: REUNIÓN LATINOAMERICANA DE PRODUCCIÓN ANIMAL, 14., 1995, Mar del Plata. Memorias... Balcarce: ALPA, 1995b. v.3-4, p.854-856.

RESTLE, J.; PASCOAL, L.L.; FATURI, C. et al. Efeito do grupo genético e da heterose nas características quantitativas da carcaça de vacas de descarte terminadas em confinamento. Revista Brasileira de Zootecnia, v.31, n.1, p.350-362, 2002 (suplemento).

RESTLE, J.; VAZ, F.N.; FEIJÓ, G.L.D. et al. Características de carcaça de bovinos de corte inteiros ou castrados de diferentes composições raciais Charolês e Nelore. Revista Brasileira de Zootecnia, v.29, n.5, p.1371-1379, 2000.

RESTLE, J.; VAZ, F.N.; QUADROS, A.R.B. et al. Características de carcaça e da carne de novilhos de diferentes genótipos de Hereford x Nelore. Revista Brasileira de Zootecnia, v.28, n.6, p.1245-1251, 1999.
STATISTICAL ANALYSES SYSTEM - SAS. SAS'S User's Guide. Cary: 1997. 46p.

SLANGER, W.D.; MARCHELLO, M.J.; DANIELSON, R.B. et al. Muscle tenderness, other carcass traits and the effect of crossbreeding on these traits in beef cattle. Journal of Animal Science, v.61, n.6, p.1402-1410, 1985.

URICK, J.J.; PAHNISH, O.F.; KNAPP, B.W. et al. Comparison of two- and three-way rotational crossing, beef $\mathrm{x}$ beef and beef $\mathrm{x}$ brown Swiss composite breed production: Postweaning growth and carcass traits. Journal of Animal Science, v.67, n.10, p.2603-2618, 1989.

VAZ, F.N. Cruzamento alternado das raças Charolês e Nelore: características de carcaça e da carne de novilhos abatidos aos dois anos. Santa Maria: Universidade Federal de Santa Maria, 1999. 58p. Dissertação (Mestrado em Zootecnia) - Universidade Federal de Santa Maria, 1999.

VAZ, F.N.; RESTLE, J. Efeito de raça e heterose para características de carcaça de novilhos da primeira geração de cruzamento entre Charolês e Nelore. Revista Brasileira de Zootecnia, v.30, n.2, p.409-416, 2001.

VAZ, F.N.; RESTLE, J.; QUADROS, A.R.B. et al. Características da carcaça e da carne de novilhos e de vacas de descarte Hereford, terminados em confinamento. Revista Brasileira de Zootecnia, v.31, n.3, p.1501-1510, 2002.

Recebido em: $27 / 05 / 04$

Aceito em: 23/02/05 